\title{
Marked increase in measles vaccination coverage among young adults in Switzerland: a campaign or cohort effect?
}

\author{
Ekkehardt Altpeter ${ }^{1} \cdot$ Monica N. Wymann ${ }^{1} \cdot$ Jean-Luc Richard ${ }^{1} \cdot$ Mirjam Mäusezahl-Feuz $^{1}$
}

Received: 9 June 2017 / Revised: 5 April 2018 / Accepted: 6 April 2018/Published online: 19 April 2018

(C) The Author(s) 2018

\begin{abstract}
Objectives To evaluate the impact of the Swiss measles elimination strategy—including a mass media campaign—on vaccination coverage and awareness among young adults aged 20-29 years.

Methods Comparison of the results of two cross-sectional population surveys in 2012 and 2015.

Results Documented vaccination coverage increased from 77 to $88 \%$ for two doses of measles vaccine. Major determinants of complete vaccination were survey year, birth cohort, sex and the absence of prior measles disease. If birth cohort and prior history of measles disease are included as factors in a multivariate model, the difference between 2012 and 2015 vanishes.

Conclusions The marked increase in complete measles vaccination coverage is due to a cohort effect, owing to the introduction of the second dose of vaccine in 1996. Most of the vaccinations were administered before the national strategy was implemented and vaccination catch-ups did not increase during the campaign in young adults. Nevertheless, this study provides evidence of an improvement in the awareness of measles and measles vaccination in young adults, which may result in an impact on measles vaccination coverage in the near future.
\end{abstract}

Keywords Measles $\cdot$ Vaccination $\cdot$ Vaccination coverage $\cdot$ Epidemiology $\cdot$ Survey

\section{Introduction}

Measles is a highly transmissible infectious disease. Its complications are particularly frequent and severe in infants and adults. However, it is possible to prevent the disease effectively with vaccination. The Swiss Federal Office of Public Health (FOPH) has recommended the vaccination of 12-month-old children against measles since 1976, and has recommended the combined vaccine against measles, rubella and mumps since 1985. In 1996, a second dose was added to the vaccination schedule for 4-7-yearold children; in 2001, the recommended age for this second dose was reduced to $15-24$ months.

Electronic supplementary material The online version of this article (https://doi.org/10.1007/s00038-018-1102-x) contains supplementary material, which is available to authorized users.

Ekkehardt Altpeter

ekkehardt.altpeter@bag.admin.ch

1 Division of Communicable Diseases, Federal Office of Public Health, Berne, Switzerland
Despite a relatively high vaccination coverage of $93 \%$ with two doses during the years 2014-2016 in the 16-yearolds, measles is still an endemic disease in Switzerland. The annual baseline incidence is low at $3-10$ cases per million people. However, a large outbreak between 2007 and 2009 led to over 4000 cases (Richard and Masserey Spicher 2009). On this occasion, Switzerland also exported measles, causing outbreaks in various European countries and the United States. In response to this national outbreak and to achieve the WHO's goal of eliminating measles in the European region by 2015 , the FOPH together with the cantons (states) and other public health partners launched a national strategy for 2011-2015 to eliminate measles (Bundesamt für Gesundheit 2013, 2016a). One of the major objectives of this strategy was to raise public awareness of measles and vaccination against this disease to sustainably increase two-dose vaccination coverage to at least $95 \%$ in children and adolescents, including through catch-up vaccinations for individuals born after 1963. The strategy consisted of six areas of intervention, including facilitating and encouraging catch-up vaccinations in the over 2-yearolds to fill vaccination gaps, as well as communication and 
promotion to raise public awareness of measles and vaccination against this disease.

Although vaccination coverage for measles has continually increased in children of all age groups since 2000, the national target of $95 \%$ of people vaccinated with two doses has not yet been reached. According to the last cantonal surveys of 2-, 8- and 16-year-olds during the period 2014-2016 (Swiss National Vaccination Coverage Survey-SNVCS), national coverage for a single dose was 94-96\% depending on age group, but only 87-93\% for two doses (Bundesamt für Gesundheit 2016b). However, a few cantons did reach $95 \%$ for two doses. Vaccination coverage of adults is not routinely monitored in Switzerland and is unknown.

The aim of this study was to assess the effect of the measles campaign in regard to improved vaccination coverage in young adults by catch-up vaccinations and increased awareness. With two consecutive surveys, we assessed the vaccination coverage as well as awareness of measles in 20-29-year-olds in 2012 before the campaign (baseline) and in 2015 afterwards (endline).

\section{Methods}

\section{Study design}

We designed two identical nationally representative crosssectional telephone surveys before and after the campaign in 2012 and 2015, respectively, conducted by the same commercial telephone survey company, using identical sampling methods and assessment tools for both baseline and endline survey. The same professional telephone survey company conducted recruitment and data collection for both surveys. The interview included the same questions regarding: participants' self-reported measles vaccination status, reasons for receiving measles catch-up vaccination, willingness to be vaccinated if vaccinations were missing and measles disease history, as well as knowledge of the disease and the elimination campaign (for the wording of the questions see Table 3). All participants were asked to send a copy of their vaccination card to the Federal Office of Public Health. The average interview time was about 7 min. The questionnaire was available in German, French and Italian. The sampling procedure and questionnaire were piloted with 38 completed interviews. The baseline survey took place between April 23 and July 22, 2012 and the second survey took place between November 9 and December 18, 2015.

The two surveys were conducted under the Swiss Epidemics Act of December 18, 1970, thus ethical committee approval was not required.

\section{Participants, recruitment and sample size}

Inclusion criteria for participation in the study were: age 20-29 years, address within Switzerland recorded in a commercial directory, and ability to answer questions in German, French or Italian. The survey company used a commercial household directory, which covers about $95 \%$ of all Swiss private households. Stratified random sampling based on two (baseline) or three (endline) language regions and municipality size was applied. Each selected household received an invitation letter from the FOPH to announce the study and its background. A total of 8645 invitation letters were sent. For households without a registered telephone number, the letter requested for it. A free telephone hotline for participants who wished to know more about the study was in place during both study periods.

The telephone contact started with a screening for willingness to participate and to assess eligibility by age. If several persons within a household fulfilled the age criteria, one was selected at random. At the end of the telephone interview, respondents were asked to send their vaccination card or a copy of it to the FOPH. The originals were returned after data collection. Those consenting to send in their vaccination card received an instruction letter with a stamped and addressed envelope and an incentive of $\mathrm{CHF}$ 10. If the FOPH did not receive the vaccination card within 3 weeks, a reminder was sent. To get the vaccination cards, a total of 2717 letters were sent followed by 1373 reminders.

We anticipated a ratio of one vaccination card received per two completed telephone interviews. The number of attempted interviews was calculated on this basis. The target sample size was 350 interviews with matching vaccination cards per language region. We aimed at a total sample size for interviews with matching vaccination cards of 700 in the baseline with two language regions and 1050 in the endline with three language regions.

\section{Statistical analyses}

We calculated sampling weights according to the same protocol for both surveys: The sampling frame was a database that covers $95 \%$ of all households in Switzerland. Weights accounted for each language region and were then calibrated to the population total considering sex and canton (Lumley 2004, 2014a).

We combined the data of the two surveys and defined an indicator variable identifying the 2012 survey as zero and the 2015 survey as one. We will call this variable 'survey' in the following. Since we did not sample data from the Italian-speaking part of Switzerland in the 2012 survey, we discarded these data from the 2015 survey for this analysis. 
Only datasets with a vaccination card were considered for the analysis, resulting in an overall total $N$ of 1851 (Fig. 1).

The primary endpoint was defined as documented vaccination with at least two doses of measles vaccine. We defined two cohorts based on the median birth year of the complete study population: one born in 1990 or later formed the reference group, while the other cohort included respondents born before 1990 . In a sensitivity analysis, we included annual birth cohort as a factor into the analyses. We recoded nationality for 2015 to the standard of 2012, since in 2012 we had two groups (Swiss and foreign nationality) and in 2015 three groups (Swiss, foreign and both). We defined people with both nationalities as Swiss.

We analysed the data excluding and including the sampling weights. For unweighted analysis, we used standard tabulations and standard inference. The level of significance was set to alpha $<0.05$. We calculated $95 \%$ confidence intervals (CI) where applicable. For the weighted analysis, we described the data by means of tabulation and calculated proportions (Thomas Lumley 2004, 2014a).
We evaluated the primary endpoint in a univariate analysis and then included all variables with a significant effect in a multivariate logistic regression model considering the survey weights and calculating odds ratios (OR) and their 95\% CI. This analysis assumes 'missing completely at random' (MCAR).

All logistic regression models (weighted as well as unweighted) were estimated with and without multiple imputations assuming a joint model (Quartagno and Carpenter 2016). The model included all categorical variables as well as age and weight as continuous variables. We estimated five imputed datasets and combined the results by means of Rubin's rule (Lumley 2014b).

We tabulated the documented vaccine coverage by cohort and the variable 'survey'. We determined the vaccination coverage at age 16-years by cohort and compared these estimates with coverage of the SNVCS for that age. We further derive the catch-up vaccination by subtracting the overall cohort-specific vaccine coverage at the age of 16 years from the overall cohort-specific vaccine coverage at the time of the interview. We restricted our analysis to the birth cohorts 1986-1992 which overlap between the

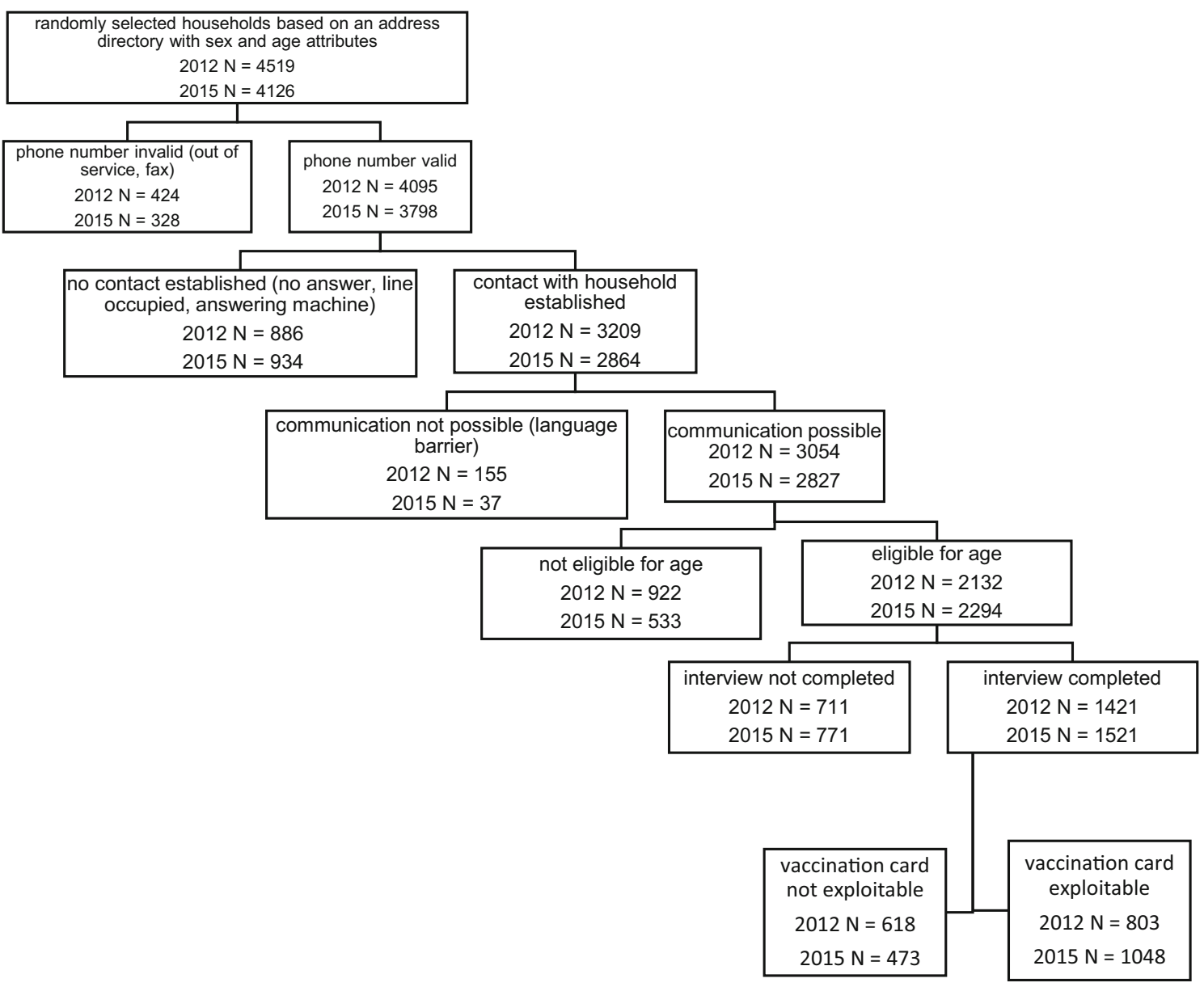

Fig. 1 Data flow chart, measles surveys 2012 and 2015, Switzerland 
two surveys and compared the vaccination coverage for at least two doses at the time of interview between the survey 2012 and 2015. We included annual birth cohort as a factor in a logistic regression model.

To evaluate the effect of absent vaccination cards, we tabulated its absence and presence, respectively, with respect to the following variables: 'survey', sex, age, language region, anamnestic vaccination status, prior measles history and estimated a linear unweighted logistic regression model.

We performed all analyses using $\mathrm{R}$ for Windows 3.1.3, respectively, 3.3.1 under Windows 7 , made available by the R Core Team (2015).

\section{Results}

\section{Response rate and basic characteristics of participants}

The response rate for completed interviews was 50\% (2012 survey 50\%, 2015 survey 49\%) and for interviews with matching vaccination card 31\% (2012 survey 28\%, 2015 survey $34 \%$ ). These proportions are calculated as follows: the proportion of observed eligible subjects was 2132 out of $3054(70 \%)$ in 2012 and 2294 out of $2827(81 \%)$ in 2015; these proportions were multiplied by the number of subjects with whom no contact could be established ( $N=886$ in 2012 and $N=934$ in 2015) or with whom no communication was possible $(N=155$ in 2012 and $N=37$ in 2015), e.g. 1041 in 2012 and 971 in 2015; these estimates were added to the number of observed eligible persons, leading to the estimated number of eligible subjects: (1041 times 2132/3054) plus 2132 in 2012 and (971 times 2294/2827) plus 2294 in 2015, i.e. 100\% of the response rate (Fig. 1). The complete combined dataset includes 2942 observations (2011 survey $N=1421,2015$ survey $N=1521)$. We included 1851 observations with valid vaccination documents in the analysis (2012 survey: $N=803$, 43\%; 2015 survey: $N=1048,57 \%)$. The two survey populations were slightly different with respect to birth year, age, sex and having children (Table 1).

We validated the question about vaccination by comparing the information given by memory and written on the vaccination card. The agreement was poor (see Table 2).

\section{Vaccination coverage}

Vaccination coverage with at least two doses increased from $77 \%$ (95\% CI $73-81 \%$ ) in 2012 to $88 \%$ (95\% CI $85-90 \%$ ) in 2015 . Only a minority was vaccinated with just one dose and the proportion decreased from $16 \%$ (95\% CI $13-19 \%$ ) in 2012 to $9 \%$ in 2015 (95\% CI 7-12\%) in favour
Table 1 Demographic characteristics, measles surveys 2012 and 2015, Switzerland

\begin{tabular}{|c|c|c|c|c|c|c|c|}
\hline & \multicolumn{2}{|c|}{$\begin{array}{l}\text { Survey } \\
2012\end{array}$} & \multicolumn{2}{|c|}{$\begin{array}{l}\text { Survey } \\
2015\end{array}$} & \multicolumn{2}{|l|}{ Total } & \multirow[t]{2}{*}{$p$ value } \\
\hline & $N$ & $\%$ & $N$ & $\%$ & $N$ & $\%$ & \\
\hline \multicolumn{8}{|l|}{ Sex } \\
\hline Female & 448 & 56 & 528 & 50 & 976 & 53 & \\
\hline Male & 355 & 44 & 520 & 50 & 875 & 47 & \\
\hline Total & 803 & 100 & 1048 & 100 & 1851 & 100 & $<0.05$ \\
\hline \multicolumn{8}{|l|}{ Age group } \\
\hline$<25$ years & 403 & 50 & 687 & 66 & 1090 & 59 & \\
\hline$>24$ years & 400 & 50 & 361 & 34 & 761 & 41 & \\
\hline Total & 803 & 100 & 1048 & 100 & 1851 & 100 & $<0.05$ \\
\hline \multicolumn{8}{|l|}{ Birth cohort } \\
\hline$\geq 1990$ & 226 & 28 & 768 & 73 & 994 & 54 & \\
\hline$<1990$ & 576 & 72 & 280 & 27 & 856 & 46 & \\
\hline Missing & 1 & 0 & 0 & 0 & 1 & 0 & \\
\hline Total & 803 & 100 & 1048 & 100 & 1851 & 100 & $<0.05$ \\
\hline \multicolumn{8}{|l|}{ Nationality } \\
\hline Swiss & 751 & 94 & 982 & 94 & 1733 & 94 & \\
\hline Foreign & 52 & 6 & 66 & 6 & 118 & 6 & \\
\hline Total & 803 & 100 & 1048 & 100 & 1851 & 100 & 0.87 \\
\hline \multicolumn{8}{|c|}{ Language region } \\
\hline German & 430 & 54 & 557 & 53 & 987 & 53 & \\
\hline French & 373 & 46 & 491 & 47 & 864 & 47 & \\
\hline Total & 803 & 100 & 1048 & 100 & 1851 & 100 & 0.86 \\
\hline \multicolumn{8}{|c|}{ Educational level } \\
\hline Secondary & 565 & 70 & 776 & 74 & 1341 & 72 & \\
\hline Tertiary & 236 & 29 & 271 & 26 & 507 & 27 & \\
\hline Missing & 2 & 0 & 1 & 0 & 3 & 0 & \\
\hline Total & 803 & 100 & 1048 & 100 & 1851 & 100 & 0.08 \\
\hline \multicolumn{8}{|l|}{$\begin{array}{l}\text { Having own } \\
\text { children }\end{array}$} \\
\hline Yes & 125 & 16 & 64 & 6 & 189 & 10 & \\
\hline No & 678 & 84 & 984 & 94 & 1662 & 90 & \\
\hline Total & 803 & 100 & 1048 & 100 & 1851 & 100 & $<0.05$ \\
\hline
\end{tabular}

of being vaccinated with more than one dose (Table 3). Most participants received their first measles vaccination according to the recommendations: the median age at uptake was 1 year, both in 2012 (interquartile range 1-2 years, $N=729$ ) and in 2015 (interquartile range $1-1$ year, $N=1006)$. The median age at the second vaccination was 13 years in 2012 (interquartile range $10-15$ years, $N=610$ ) and 10 years in 2015 (interquartile range $7-13$ years, $N=923$ ). Very few second doses and even fewer first doses were received between the ages of 20 and 29 years (Fig. 2) in both surveys. According to the 2015 survey, only 4\% of respondents (37/932) received their second dose after 2011, the year a national measles vaccination campaign was launched, compared to $8 \%$ of 
Table 2 Agreement between anamnesis and documented measles vaccination by use of the vaccination document at interview, measles survey 2012 and 2015, Switzerland

\begin{tabular}{|c|c|c|c|c|c|}
\hline & \multicolumn{5}{|c|}{ Documented number of doses } \\
\hline & 0 & 1 & 2 & 3 & Total \\
\hline \multicolumn{6}{|c|}{ Vaccination document used during interview } \\
\hline \multicolumn{6}{|c|}{ Have you been vaccinated against measles? } \\
\hline Yes & $5(1.2 \%)$ & $48(11.8 \%)$ & $304(74.5 \%)$ & $34(8.3 \%)$ & $391(95.8 \%)$ \\
\hline No & $5(1.2 \%)$ & $2(0.5 \%)$ & $6(1.5 \%)$ & $1(0.2 \%)$ & $14(3.4 \%)$ \\
\hline I do not know & $1(0.2 \%)$ & $0(0 \%)$ & $2(0.5 \%)$ & $0(0 \%)$ & $3(0.7 \%)$ \\
\hline Total & & & & & $408(100 \%)$ \\
\hline \multicolumn{6}{|c|}{ Vaccination document not used during interview } \\
\hline \multicolumn{6}{|c|}{ Have you been vaccinated against measles? } \\
\hline Yes & $26(1.8 \%)$ & $122(8.4 \%)$ & $886(61.3 \%)$ & $91(6.3 \%)$ & $1125(77.8 \%)$ \\
\hline No & $34(2.4 \%)$ & $19(1.3 \%)$ & $56(3.9 \%)$ & $2(0.1 \%)$ & $111(7.7 \%)$ \\
\hline I do not know & $13(0.9 \%)$ & $21(1.5 \%)$ & $159(11.0 \%)$ & $17(1.2 \%)$ & $210(14.5 \%)$ \\
\hline Total & & & & & $1446(100.0 \%)$ \\
\hline
\end{tabular}

respondents (46/610) during an equally long time span after 2008 for the 2012 survey $(\mathrm{OR}=0.51$, 95\% CI 0.32-0.81). However, the catch-up needs for second doses 3 years before the start of the respective survey were lower in $2015(151 / 932=16 \%)$ than in $2012(228 / 610=37 \%)$ $(\mathrm{OR}=0.32,95 \%$ CI $0.25-0.41)$. Accordingly, these catchup vaccinations with a second dose during the campaign covered $25 \%$ of the needs in 2015 respondents compared to $20 \%$ in 2012 (OR $=1.28,95 \%$ CI 0.76-2.16). There is a strong cohort effect on the complete vaccination coverage (supplementary material Tables 3 and 4).

\section{Knowledge about vaccination}

Awareness of measles and measles vaccination improved between 2012 and 2015 (Table 3). First, significantly more participants knew that adults can get measles: $32 \%$ in 2012 (95\% CI 28-36\%) were sure that adults can get measles compared to $41 \%$ in 2015 (95\% CI 37-45\%). Second, there was a trend, although not statistically significant, for more participants to be sure that they could get missing vaccinations as adults: from $18 \%$ in 2012 (95\% CI 14-21\%) to $23 \%$ in 2015 (95\% CI 19-26\%). There was practically no change with respect to the other questions on awareness. In both surveys, a similarly low proportion had previously contracted measles. About a quarter of participants had professional contacts to risk groups (Table 3).

\section{Determinants of vaccination}

In the weighted univariate analysis, we identified the following factors as significantly associated with complete vaccination:'survey', birth cohort, sex, educational level and prior measles (Table 4). All these factors except educational level remained statistically significant in the multivariate analysis. Thus, the major determinants of complete measles vaccination were the year of the survey, i.e. respondents surveyed in 2015 were more likely to be fully vaccinated than those surveyed in 2012; birth cohort, i.e. persons born in 1990 or after were more likely to be fully vaccinated than those born before 1990; sex, i.e. females were more likely to be fully vaccinated than males; and prior measles, i.e. those who were sure that they had not had measles were more likely to be fully vaccinated than those with measles in their medical history (Table 4).

\section{Sensitivity analyses}

The sensitivity analysis either neglecting the weights, assuming 'missing completely at random' or 'missing at random' and their combination confirmed the results of the weighted univariate and multivariate analysis (supplementary material Tables 1 and 2).

There is a strong cohort effect on the primary endpoint complete vaccination coverage. If the analysis is restricted to the birth cohorts 1986-1992, the odds ratio between 2012 and 2015 is 1.40 (95\% CI 0.87-2.10). In the multivariate analysis, this estimate drops to 1.29 (95\% CI 0.82-2.03) (supplementary material Tables 3 and 4).

The participants with and without vaccination cards are different with respect to the factors 'survey', age, language region and anamnestic vaccination status (supplementary material Table 5). There were more missing vaccination cards in 2012 compared to 2015 . In both surveys, $82 \%$ of respondents reported during the telephone interview to be completely vaccinated, which contrasted with information gained from the vaccination cards. 
Table 3 Vaccination coverage and knowledge about measles, measles surveys 2012 and 2015, Switzerland

\begin{tabular}{|c|c|c|c|c|c|c|c|c|}
\hline \multirow{3}{*}{$\begin{array}{l}\text { Documented measles } \\
\text { vaccination }\end{array}$} & \multicolumn{4}{|c|}{ Survey 2012} & \multicolumn{4}{|c|}{ Survey 2015} \\
\hline & \multirow[t]{2}{*}{$N^{\mathrm{a}}$} & \multirow[t]{2}{*}{$\%$} & \multicolumn{2}{|c|}{$95 \% \mathrm{CI}$} & \multirow[t]{2}{*}{$N$} & \multirow[t]{2}{*}{$\%$} & \multicolumn{2}{|l|}{$95 \% \mathrm{CI}$} \\
\hline & & & & & & & & \\
\hline Not vaccinated & 51 & 7 & 5 & 9 & 30 & 3 & 2 & 4 \\
\hline 1 dose & 130 & 16 & 13 & 19 & 82 & 9 & 7 & 12 \\
\hline 2 doses & 577 & 71 & 67 & 75 & 836 & 78 & 75 & 81 \\
\hline 3 doses & 45 & 6 & 4 & 8 & 100 & 10 & 7 & 12 \\
\hline \multicolumn{9}{|c|}{$\begin{array}{l}\text { Vaccinated with at least two } \\
\text { doses }\end{array}$} \\
\hline No & 181 & 23 & 19 & 27 & 112 & 12 & 10 & 15 \\
\hline Yes & 622 & 77 & 73 & 81 & 936 & 88 & 85 & 90 \\
\hline \multicolumn{9}{|l|}{ Prior measles disease } \\
\hline Surely yes & 55 & 7 & 5 & 10 & 82 & 8 & 6 & 10 \\
\hline Rather yes & 31 & 5 & 3 & 7 & 32 & 3 & 2 & 5 \\
\hline Rather no & 113 & 12 & 9 & 15 & 176 & 19 & 16 & 23 \\
\hline Surely no & 570 & 70 & 65 & 74 & 723 & 65 & 61 & 69 \\
\hline I do not know & 34 & 6 & 3 & 8 & 35 & 4 & 2 & 6 \\
\hline \multicolumn{9}{|l|}{ Can adults get measles? } \\
\hline Surely yes & 280 & 32 & 28 & 36 & 374 & 41 & 37 & 45 \\
\hline Rather yes & 402 & 53 & 48 & 57 & 529 & 48 & 44 & 52 \\
\hline Rather no & 56 & 7 & 5 & 9 & 72 & 6 & 4 & 8 \\
\hline Surely no & 8 & 0 & 0 & 1 & 11 & 1 & 0 & 1 \\
\hline I do not know & 57 & 8 & 5 & 10 & 62 & 5 & 3 & 6 \\
\hline \multicolumn{9}{|c|}{$\begin{array}{l}\text { Can adults catch up missing } \\
\text { vaccinations? }\end{array}$} \\
\hline Surely yes & 147 & 18 & 14 & 21 & 200 & 23 & 19 & 26 \\
\hline Rather yes & 408 & 51 & 47 & 56 & 566 & 51 & 47 & 55 \\
\hline Rather no & 100 & 14 & 11 & 17 & 132 & 14 & 11 & 17 \\
\hline Surely no & 28 & 3 & 1 & 5 & 17 & 1 & 0 & 2 \\
\hline I do not know & 120 & 14 & 11 & 17 & 133 & 11 & 9 & 13 \\
\hline \multicolumn{9}{|c|}{$\begin{array}{l}\text { I can endanger others if I am } \\
\text { not vaccinated }\end{array}$} \\
\hline Complete agreement & 345 & 42 & 38 & 47 & 451 & 44 & 41 & 48 \\
\hline Slight agreement & 287 & 36 & 31 & 40 & 405 & 37 & 34 & 41 \\
\hline Slight disagreement & 94 & 13 & 10 & 16 & 148 & 15 & 12 & 18 \\
\hline Complete disagreement & 46 & 5 & 3 & 7 & 26 & 2 & 1 & 3 \\
\hline I do not know & 31 & 4 & 2 & 6 & 18 & 1 & 0 & 2 \\
\hline \multicolumn{9}{|c|}{$\begin{array}{l}\text { Is vaccination against measles } \\
\text { mandatory in Switzerland? }\end{array}$} \\
\hline Surely yes & 41 & 5 & 3 & 7 & 60 & 5 & 3 & 6 \\
\hline Yes, I believe so & 106 & 13 & 10 & 16 & 159 & 13 & 11 & 16 \\
\hline No, I do not believe so & 281 & 32 & 28 & 36 & 410 & 37 & 34 & 41 \\
\hline Surely no & 317 & 44 & 39 & 48 & 379 & 42 & 38 & 46 \\
\hline I do not know & 58 & 6 & 4 & 7 & 40 & 3 & 2 & 4 \\
\hline
\end{tabular}


Table 3 (continued)

\begin{tabular}{|c|c|c|c|c|c|c|c|c|}
\hline & \multicolumn{4}{|c|}{ Survey 2012} & \multicolumn{4}{|c|}{ Survey 2015} \\
\hline & $N^{\mathrm{a}}$ & $\%$ & $95 \%$ & & $N$ & $\%$ & $95 \% \mathrm{CI}$ & \\
\hline \multicolumn{9}{|c|}{$\begin{array}{l}\text { Did you know about the } \\
\text { collaboration of Switzerland } \\
\text { with the WHO in } \\
\text { eliminating measles? }\end{array}$} \\
\hline Yes & 287 & 38 & 33 & 42 & 438 & 44 & 40 & 48 \\
\hline No & 516 & 62 & 58 & 67 & 610 & 56 & 52 & 60 \\
\hline \multicolumn{9}{|c|}{$\begin{array}{l}\text { Is measles elimination } \\
\text { necessary in Switzerland? }\end{array}$} \\
\hline Surely yes & 332 & 38 & 34 & 43 & 361 & 34 & 30 & 38 \\
\hline Rather yes & 285 & 35 & 31 & 39 & 393 & 37 & 33 & 41 \\
\hline Rather no & 102 & 15 & 12 & 18 & 177 & 18 & 15 & 21 \\
\hline Surely no & 40 & 5 & 3 & 7 & 44 & 5 & 3 & 6 \\
\hline I do not know & 44 & 7 & 4 & 9 & 73 & 7 & 5 & 9 \\
\hline \multicolumn{9}{|c|}{$\begin{array}{l}\text { Do you have professional } \\
\text { contact to children, pregnant } \\
\text { women or sick persons? }\end{array}$} \\
\hline Yes & 259 & 28 & 24 & 32 & 302 & 25 & 22 & 29 \\
\hline No & 544 & 72 & 68 & 76 & 745 & 75 & 71 & 78 \\
\hline Missing & 0 & & & & 1 & & & \\
\hline
\end{tabular}

Percent taking into account the weighting. Deviations from the total of 100 per cent is due to rounding errors

${ }^{a} N$ total: 803 for measles survey 2012, 1048 for measles survey 2015

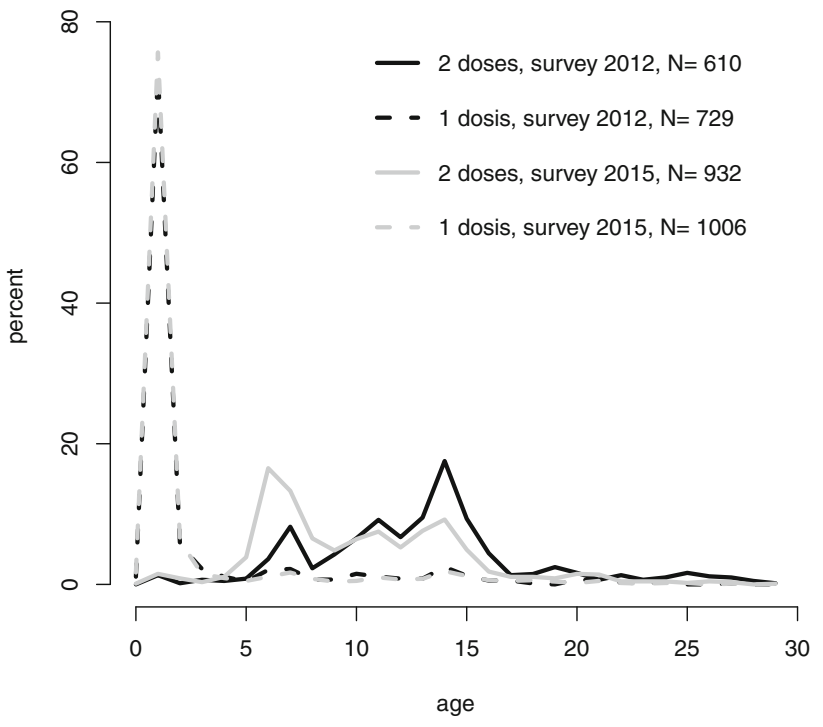

Fig. 2 Age distribution at first and second dose of vaccination, 2012 and 2015 measles surveys, Switzerland

\section{Discussion}

\section{Main results}

While routine monitoring of vaccination coverage is almost universally established for measles in children and adolescents, it generally does not include adults. The results of this study provide the first reliable estimates of measles vaccination coverage in young adults in Switzerland.

We assessed vaccination coverage and determinants of vaccination among young adults by comparing the results of two cross-sectional surveys conducted in 2012 and 2015. Documented complete vaccination increased from 77 to $88 \%$. However, there is no evidence for an association between vaccination and the recent national awareness campaign or increased awareness. Knowing that measles can also affect adults was the only factor that increased between the two surveys, but this knowledge was not related to the likelihood of vaccination.

\section{Strengths and limitations}

The careful sampling mechanism stratified by sex and language region, the adequately high sample size of valid vaccination card-based data, the thorough statistical analysis taking into account various sensitivity analyses for missing data and weighting, as well as application of the identical questionnaire tools make us confident of the quality of the estimate as well as the significant increase in vaccination coverage between 2012 and 2015. However, the marked increase in vaccination coverage is very likely due to a cohort effect. This cohort effect, unexpected at the design stage of the studies, is so strong, that all multivariate analyses have to be interpreted with care. The observed 
Table 4 Logistic regression models of documented vaccination coverage with at least two doses, weighted and assuming missing completely at random, measles survey 2012 and 2015, Switzerland

\begin{tabular}{|c|c|c|c|c|c|c|}
\hline & \multicolumn{3}{|c|}{ Univariate analysis } & \multicolumn{3}{|c|}{ Multivariate analysis } \\
\hline & OR & $95 \%$ & & Adj. OR & $95 \%$ & \\
\hline \multicolumn{7}{|l|}{ Survey } \\
\hline 2012 & 1 & & & 1 & & \\
\hline 2015 & 2.15 & 1.54 & 3.01 & 1.67 & 1.15 & 2.42 \\
\hline \multicolumn{7}{|l|}{ Birth cohort } \\
\hline$\geq 1990$ & 1 & & & 1 & & \\
\hline$<1990$ & 0.32 & 0.23 & 0.45 & 0.41 & 0.28 & 0.61 \\
\hline \multicolumn{7}{|l|}{ Sex } \\
\hline Female & 1 & & & 1 & & \\
\hline Male & 0.59 & 0.42 & 0.81 & 0.58 & 0.42 & 0.82 \\
\hline \multicolumn{7}{|l|}{ Nationality } \\
\hline Swiss & 1 & & & n.i. & & \\
\hline Foreign & 1.15 & 0.59 & 2.23 & n.i. & & \\
\hline \multicolumn{7}{|l|}{ Language region } \\
\hline German & 1 & & & n.i. & & \\
\hline French & 1.11 & 0.83 & 1.48 & n.i. & & \\
\hline \multicolumn{7}{|l|}{ Educational level } \\
\hline Secondary & 1 & & & 1 & & \\
\hline Tertiary & 0.60 & 0.43 & 0.86 & 0.77 & 0.53 & 1.12 \\
\hline \multicolumn{7}{|l|}{ Having own children } \\
\hline Yes & 1 & & & n.i. & & \\
\hline No & 1.48 & 0.96 & 2.31 & n.i. & & \\
\hline \multicolumn{7}{|l|}{ Prior measles } \\
\hline Surely yes & 1 & & & 1 & & \\
\hline Yes, I believe so & 1.43 & 0.62 & 3.28 & 1.69 & 0.71 & 4.05 \\
\hline No, I do not believe so & 1.79 & 0.97 & 3.31 & 1.83 & 0.94 & 3.54 \\
\hline Surely not & 2.33 & 1.40 & 3.89 & 2.46 & 1.43 & 4.23 \\
\hline I do not know & 1.19 & 0.49 & 2.91 & 1.51 & 0.61 & 3.77 \\
\hline \multicolumn{7}{|l|}{ Can adults get measles? } \\
\hline Surely yes & 1 & & & n.i. & & \\
\hline Rather yes & 1.13 & 0.79 & 1.62 & n.i. & & \\
\hline Rather no & 0.98 & 0.52 & 1.86 & n.i. & & \\
\hline Surely no & 0.85 & 0.25 & 2.89 & n.i. & & \\
\hline I do not know & 0.93 & 0.50 & 1.74 & n.i. & & \\
\hline \multicolumn{7}{|c|}{ Can adults catch up missing vaccinations? } \\
\hline Surely yes & 1 & & & n.i. & & \\
\hline Rather yes & 1.00 & 0.66 & 1.53 & n.i. & & \\
\hline Rather no & 0.77 & 0.44 & 1.36 & n.i. & & \\
\hline Surely no & 1.65 & 0.63 & 4.37 & n.i. & & \\
\hline I do not know & 0.89 & 0.51 & 1.55 & n.i. & & \\
\hline \multicolumn{7}{|c|}{ I can endanger others if I am not vaccinated } \\
\hline Complete agreement & 1 & & & n.i. & & \\
\hline Slight agreement & 0.76 & 0.52 & 1.10 & n.i. & & \\
\hline Slight disagreement & 0.78 & 0.48 & 1.27 & n.i. & & \\
\hline Complete disagreement & 0.74 & 0.38 & 1.41 & n.i. & & \\
\hline I do not know & 1.60 & 0.40 & 6.45 & n.i. & & \\
\hline
\end{tabular}


Table 4 (continued)

\begin{tabular}{|c|c|c|c|c|c|}
\hline & \multicolumn{3}{|c|}{ Univariate analysis } & \multicolumn{2}{|c|}{ Multivariate analysis } \\
\hline & OR & $95 \%$ & & Adj. OR & $95 \% \mathrm{CI}$ \\
\hline \multicolumn{6}{|c|}{$\begin{array}{l}\text { Is vaccination against measles mandatory in } \\
\text { Switzerland? }\end{array}$} \\
\hline Surely yes & 1 & & & n.i. & \\
\hline Yes, I believe so & 2.06 & 0.73 & 5.83 & n.i. & \\
\hline No, I do not believe so & 0.96 & 0.38 & 2.45 & n.i. & \\
\hline Surely no & 0.90 & 0.35 & 2.27 & n.i. & \\
\hline I do not know & 1.33 & 0.43 & 4.09 & n.i. & \\
\hline \multicolumn{6}{|c|}{$\begin{array}{l}\text { Did you know about the collaboration of } \\
\text { Switzerland with the WHO in eliminating } \\
\text { measles? }\end{array}$} \\
\hline Yes & 1 & & & n.i. & \\
\hline No & 0.99 & 0.71 & 1.38 & n.i. & \\
\hline \multicolumn{6}{|c|}{$\begin{array}{l}\text { Is measles elimination necessary in } \\
\text { Switzerland? }\end{array}$} \\
\hline Surely yes & 1 & & & n.i. & \\
\hline Rather yes & 1.06 & 0.72 & 1.57 & n.i. & \\
\hline Rather no & 0.73 & 0.46 & 1.17 & n.i. & \\
\hline Surely no & 1.43 & 0.67 & 3.04 & n.i. & \\
\hline I do not know & 1.03 & 0.55 & 1.91 & n.i. & \\
\hline \multicolumn{6}{|c|}{$\begin{array}{l}\text { Do you have professional contact to children, } \\
\text { pregnant women or sick persons? }\end{array}$} \\
\hline Yes & 1 & & & n.i. & \\
\hline No & 0.95 & 0.65 & 1.38 & n.i. & \\
\hline
\end{tabular}

OR odds ratio, $C I$ confidence interval, $n . i$. not included into the multivariate model

cohort effect is confirmed by the comparison with the values from the external reference the SNVCS, which also shows the increasing values over the study periods of the SNVCS.

The high number of missing vaccination cards-an exclusion criterion of our study - could lead to a selection bias. The contrast between self-reported vaccination status and documented vaccination history confirms our study design, which focused on the collection of vaccination cards and restricted the analysis on these written records. The return rate of vaccination cards $(63 \%)$ was in the range of the expectation during the design stage and was anticipated in the sample size calculation for interviews with matching vaccination cards. However, there is evidence that subjects with missing vaccination cards are different between the two surveys, with respect to age, language region, and history of measles vaccination. The process of differential missing data between 2012 and 2015 may lead to an overestimation of the marked increase in vaccination coverage.

There are some critical points with respect to our analysis. The participants were asked about vaccinations that often occurred during their early infancy. Anamnestic information about their vaccination status, provided by participants not consulting their vaccination card, was often uncertain (see Table 2). We therefore restricted our analyses to individuals who provided a vaccination card, thereby reducing response rate from 50 to $31 \%$. This could have introduced selection bias and led us to overestimate the effect, because we assume that people without a vaccination card are less likely to be vaccinated. However, this was partially addressed by a complex weighting procedure, a common method of dealing with the unit non-response. After weighting, the study population had a similar distribution to the Swiss general population in this age range in regard to age, sex and cantonal distribution.

Our results are in line with the vaccination coverage in the 16-year-old in the SNVCS (Bundesamt für Gesundheit 2016b). They are as well comparable to findings from Germany and France. In a study, conducted 2012 in Germany, vaccination coverage for two doses was found to be $56 \%$ in adults aged 20-34 years (Schuster et al. 2015). 80\% of these participants relied on their vaccination card to answer. Furthermore, the fact that in our study younger age groups and females were more likely to be vaccinated is consistent with the finding of Schuster et al. (2015). In 
France, measles vaccination coverage (based on vaccination cards of first-year health care students) was $78 \%$ in 2011 (Faure et al. 2013). In another French study in 2015, coverage was 93\% in 16-18-year-olds (Buscail and Gagnière 2016).

Our results show that the sharp increase of vaccination coverage in just 3 years was very likely due to a "cohort effect" resulting from a change in recommendations made in 1996: a second dose of measles vaccine was introduced to the national vaccination plan for 4-7-year-old children, together with the recommendation to catch up at any age. Only four out of ten birth cohorts (1989-1992) among the participants in the first survey had the opportunity to receive a second dose as routine vaccination, compared to seven cohorts (1989-1995) of participants in the second survey in 2015. In addition, it took a few years for the second dose to become a well-established practice. The gap of catch-up vaccinations with a second dose 3 years before the surveys was therefore larger in the group surveyed in 2012 than that in 2015.

Most of these catch-up vaccinations were administered before the age of 16 years. They were received before the recent promotion campaign and should be credited to paediatricians, school health services and parents. Although one quarter of the pre-campaign vaccination gaps were filled during the campaign, this proportion was not significantly higher than during the 3 years before the campaign suggesting that the campaign had little to no effect on the number of catch-up doses administered.

We estimated the number of catch-up vaccinations administered by primary care physicians in a study within the Swiss Sentinella network (Bundesamt für Gesundheit 2016c). In 2014 and 2015, estimated totals of 33,000 and 37,000 doses of measles catch-up vaccinations were administered by general practitioners and paediatricians. This corresponds to $37 \%$ of all doses needed in 2015 to close the estimated gap (with a 95\% objective) in measles vaccination for 2-51-year-olds in Switzerland. Two-thirds of these catch-up vaccinations were given to adults aged 20 years and older. Eighty-eight percent of all vaccinations were initiated by the physicians, underlining their crucial role in promoting vaccination and filling the gaps.

Awareness of measles has increased slightly in our study and can almost be considered as "common sense", with $89 \%$ of all people knowing that measles can also affect adults. There mere fact that the study topic was measles elimination and the interviewees were primed by an invitation letter sent out by the FOPH may lead to overestimating results about knowledge and attitude towards measles elimination. Knowledge and attitude questions were highly correlated in our survey. But the data were too scarce to be stratified by all variables and evaluated in an integrated way. In addition, there is no simple and direct causal pathway between knowledge, attitude and actual vaccination; this leads to an inconclusive effect, a problem that was encountered by Larson et al. (2014).

\section{Conclusion}

An $11 \%$ increase in measles vaccination coverage within a 3 -year period in a population where vaccination coverage is already high is a historic finding. This marked increase in measles vaccination coverage is, however, due to a cohort effect, owing to the introduction of the second dose of vaccine in 1996 in the national vaccination plan. This study provides evidence of an improvement in the awareness about measles and measles vaccination in young adults, which may result in an impact on measles vaccination coverage in the future. The achievement of this marked increase in measles vaccination coverage merits acknowledgment of the efforts made by general practitioners and paediatricians in Switzerland, who remain the main and the most important promoters for measles vaccination. Governments at all levels are challenged to use their leeway to support any efforts made by Swiss physicians to promote vaccination in general.

Funding This study was fully funded by the Swiss government (Swiss Federal Office of Public Health) based on the federal epidemic law (EpG, SR 818.101 of December 18, 1970).

\section{Compliance with ethical standards}

Conflict of interest The authors declare that they have no conflict of interest.

Ethical approval We conducted this survey as an evaluation of ongoing surveillance of vaccination coverage according to the Swiss law on communicable diseases in 2012 and 2015 (EpG, SR 818.101 of December 18, 1970).

Informed consent Informed consent was obtained from all individual participants included in the study.

Open Access This article is distributed under the terms of the Creative Commons Attribution 4.0 International License (http://creative commons.org/licenses/by/4.0/), which permits unrestricted use, distribution, and reproduction in any medium, provided you give appropriate credit to the original author(s) and the source, provide a link to the Creative Commons license, and indicate if changes were made.

\section{References}

Bundesamt für Gesundheit (2013) Nationale Strategie zur Masernelimination 2011-2015. BAG Bull 17:269-271

Bundesamt für Gesundheit (2016a) Schweiz ohne Masern. BAG Bull 5:93-95 
Bundesamt für Gesundheit (2016b) Durchimpfung von 2-, 8- und 16-jährigen Kindern in der Schweiz, 1999-2016. https://www. bag.admin.ch/bag/de/home/themen/mensch-gesundheit/ueber tragbare-krankheiten/impfungen-prophylaxe/informationenfachleute-gesundheitspersonal/durchimpfung.html. Accessed 22 Nov 2017

Bundesamt für Gesundheit (2016c) Nachholimpfung gegen Masern und Auffrischimpfung gegen Keuchhusten: wesentlicher Beitrag zur Masernelimination und zum Schutz von Säuglingen. BAG Bull 35:533-541

Buscail C, Gagnière B (2016) Vaccination coverage of adolescents: results of a Defense and Citizenship Day-based survey. Med Mal Infect 46(1):25-31. https://doi.org/10.1016/j.medmal.2015.11. 010

Faure E, Cortot C, Gosset D, Cordonnier A, Deruelle P, Guery B (2013) Vaccinal status of healthcare students in Lille. Med Mal Infect 43(3):114-117. https://doi.org/10.1016/j.medmal.2013.02. 002

Larson HJ, Jarrett C, Eckersberger E, Smith DMD, Paterson P (2014) Understanding vaccine hesitancy around vaccines and vaccination from a global perspective: a systematic review of published literature, 2007-2012. Vaccine 32(19):2150-2159
Lumley T (2004) Analysis of complex survey samples. J Stat Softw 9(1):1-19

Lumley T (2014a) Survey: analysis of complex survey samples. R package version 3.30

Lumley T (2014b) mitools: Tools for multiple imputation of missing data. $\mathrm{R}$ package version 2.3. http://CRAN.R-project.org/pack age=mitools. Accessed 22 Nov 2017

Quartagno M and Carpenter J (2016) jomo: a package for multilevel joint modelling multiple imputation. http://CRAN.R-project.org/ package=jomo. Accessed 22 Nov 2017

Richard JL, Masserey Spicher V (2009) Large measles epidemic in Switzerland from 2006 to 2009: consequences for the elimination of measles in Europe. Eur Surveill 14(50):pii: 19443

R Core Team (2015) R: a language and environment for statistical computing. R Foundation for Statistical Computing, Vienna, Austria. http://www.R-project.org/. Accessed 22 Nov 2017

Schuster M, Stelzer T, Burckhardt F (2015) Why are young adults affected? Estimating measles vaccination coverage in 20-34 year old Germans in order to verify progress towards measles elimination. PLoS Curr 7:pii: ecurrents.outbreaks.0a2d3e9 465f067a0b2933d598d504d2e. https://doi.org/10.1371/currents. outbreaks.0a2d3e9465f067a0b2933d598d504d2e 